\title{
Morphological and morphometric analysis of the Italian honeybee (Apis mellifera ligustica) spermatozoa: a preliminary study in Campania region
}

\author{
Karen Power*, Emanuele D’Anza, Manuela Martano, Sara Albarella, Francesca Ciotola, Vincenzo Peretti and Paola Maiolino
}

*Correspondence: Karen.power@unina.it

CrossMark

$\leftarrow$ Click for updates

Department of Veterinary Medicine and Animal Production, University of Naples “Federico II"-Via Delpino, 1, 80137, Naples, Italy.

\begin{abstract}
Background: Since few decades, the world is facing important losses in the number of honeybees, with great threat to the agro-zootechnic economics and to the global biodiversity. It is well known that stressors can affect the female and male reproductive system, impairing queens' and drones' fertility. To date, still very little is known about drones' physiological characteristics and possible alterations of the reproductive activity. This study focused on describing the morphological features and morphometric parameters of the Italian honeybee (Apis mellifera ligustica) spermatozoa in order to define its standard characteristics.
\end{abstract}

Findings: The following morphometric values (mean \pm standard deviation) were measured: sperm total length $(230,81 \pm 17,22 \mu \mathrm{m})$, tail length $(222,96 \pm 17,15 \mu \mathrm{m})$, head length $(7,85 \pm 0,65 \mu \mathrm{m})$, nucleus length $(4,44 \pm 0,61 \mu \mathrm{m})$ and perforator length $(3,58 \pm 1,21 \mu \mathrm{m})$. Moreover, $7 \%$ of the spermatozoa exhibited alterations such as broken and double tails.

Conclusions: The results obtained, allow a preliminary definition of measures of $A$. mellifera ligustica spermatozoa using an easy and economical protocol that could help to study the morphology and the morphometry of drone spermatozoa and to point out possible alterations.

Keywords: Apis mellifera, drone, spermatozoa, standard measurements

\section{Introduction}

Over the past few decades, the influence of various stressors such as pathogens, agrochemicals, environmental changes, pollution, monocultures, poor flowering habitats has caused the reduction in the number of honeybees [1]. It has been shown that some of these factors are able to directly or indirectly reduce fertility in honeybees [2]. To date, studies on honeybees' reproduction have focused on the female aspect of reproduction, as the hypofertility of the queen appears evident thanks to signs such as: decrease of brood; abnormal pattern of the brood; excessive number of drones; early replacement of the queen and presence of orphan colonies [3]. Less attention has been paid to drones and even less to alterations of their fertility, although it has been shown that male hypofertility/ infertility is as complex as that of females [4]. In order to study any possible alteration in the fertility of drones, it is important to establish as a starting point what is normal. The aim of this study was to describe the morphological characteristics and morphometric parameters of the Italian honeybee (Apis mellifera ligustica) spermatozoa in order to define standard features that could be used in further studies to show possible alterations.

\section{Materials and methods}

100 mature drones (16-18 days old) of A. mellifera ligustica (Hymenoptera, Apidae) were captured in different apiaries located in Campania (Italy) during March-June 2017, when drones are mostly produced. After being sacrificed, the dissection of the abdomen was performed under a dissecting microscope (Optika, Italy) as described by Carreck et al. [5]. The reproductive system (testes, seminal vesicles and mucus glands) was then 
Power et al. Veterinary Medicine and Animal Sciences 2019,

removed and placed in a $1.5 \mathrm{ml}$ tube (Eppendorf, Germany) containing $500 \mu$ l of $0.9 \%$ sodium chloride solution (Galenica Senese, Italy). The tubes containing the samples were then centrifuged (Centrifuge 5424, Eppendorf, Germany) at 250g for 10 minutes; a drop of pellet was swiped on a slide, stained with hematoxylin and eosin and observed with a Nikon ECLIPSE 80i (Nikon, Tokyo) microscope (100X objective, 10X ocular).

Morphological analysis was performed on 10 spermatozoa per sample (1000 total spermatozoa), while morphometric analysis was performed only on healthy spermatozoa. Total length of the sperm, tail length, nucleus length, head and perforator length were measured using image analysis software (Nikon NIS Elements 4.00.02, Nikon, Tokyo ). Starting and end point of measurement are reported in Table 1. Mean values and standard deviation were calculated for each parameter.

Table 1. Morphometric parameters of A. mellifera ligustica spermatozoa.

\begin{tabular}{lll}
\hline Parameter & $\begin{array}{l}\text { Starting and end } \\
\text { point of measurement }\end{array}$ & $\begin{array}{l}\text { mean value } \pm \\
\text { standard } \\
\text { deviation }(\mu \mathrm{m})\end{array}$ \\
\hline Total sperm length & $\begin{array}{l}\text { Anterior tip of the } \\
\text { perforator-caudal tip of } \\
\text { the tail }\end{array}$ & $230.81 \pm 17.22$ \\
\hline Tail length & $\begin{array}{l}\text { point of insertion of } \\
\text { the tail in the nucleus } \\
\text {-caudal tip of the tail }\end{array}$ & $222.96 \pm 17.15$ \\
\hline Head length & $\begin{array}{l}\text { Anterior tip of the } \\
\text { perforator- point of } \\
\text { insertion of perforator } \\
\text { in the nucleus }\end{array}$ & \\
\hline Nucleus length & $\begin{array}{l}\text { Caudal tip of the } \\
\text { perforator- point of } \\
\text { insertion of the tail in } \\
\text { the nucleus }\end{array}$ & \\
\hline Perforator length & $\begin{array}{l}\text { Anterior tip of the } \\
\text { perforator-point of } \\
\text { insertion of perforator } \\
\text { in the nucleus }\end{array}$ \\
\hline
\end{tabular}

\section{Results and discussion}

The spermatozoa of the Italian honeybee, stained with hematoxylin-eosin, are characterised by a long tail and an elongated head, formed by a nucleus and a perforator (Figure 1). Morphometric parameters (mean values and standard deviation) are summarized in Table 1. Moreover, $7 \%(n=70)$ of the samples revealed visible defects, such as split and broken tails (Figure 1).

To date, many of the studies have focused on the vitality and motility of sperm and little importance has been given to the study of morphometrics, morphology and possible alterations, although considered of predictive value of infertility in many species [6-7].

To our knowledge this is the first study to analyze mo phological and morphometric characteristics of the Italian honeybee

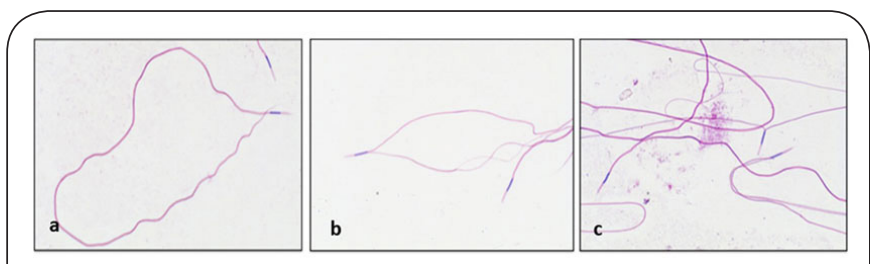

Figure 1. Apis mellifera ligustica spermatozoa.

a) normal spermatozoa showing no morphological alterations (haematoxylin and eosin staining, x100).

b) abnormal spermatozoa showing double and broken tails (haematoxylin and eosin staining, x100).

c) abnormal spermatozoa showing broken tails (haematoxylin and eosin staining, x100).

spermatozoa and reveal the presence of morphological abnormalities.

Hymenoptera spermatozoa have an elongated nucleus that can be straight and rigid, spiraled, or irregular and more flexible.

The acrosome is of variable size and structure depending on the species. Most hymenopteran spermatozoa presents the perforator, a granular structure that stretches from the acrosome to the front of the nucleus [8].

The spermatozoa of $A$. mellifera, as described by Peng [9] are long and filamentous, with a total length of about 250-270 $\mu \mathrm{m}$, the head measures 8-10 $\mu \mathrm{m}$ and the total length of the acrosomal complex measures $5 \mu \mathrm{m}$. A study by Gontarz et al. [10] has focused the attention on the analysis of Apis mellifera carnica spermatozoa and the results are shown in Table 2.

In our study Italian honeybee spermatozoa appeared smaller with a mean total length of $230,81(S D \pm 17,22) \mu \mathrm{m}$. It has been shown that the production of short sperm cells consumes less energy allowing the production of a greater number of spermatozoa and the reduction of the resources allocated to the production of the spermatozoa themselves [11]. Furthermore, shorter sperm cells allow more sperm to be stored in the queen's spermateca, resulting in greater long-term fertilization potential [12]. However, according to Rhodes et al. [13] sperm volume and sperm concentration in drones depend on their genotype and to a lesser extent to their age and season of the year.

Our results show the presence of a high variability of the total length of spermatozoa, as underlined by the SD values

Table 2. Morphometric parameters of A. mellifera carnica spermatozoa [14].

\begin{tabular}{ll}
\hline Parameter & Mean value \pm Standard deviation $(\boldsymbol{\mu m})$ \\
\hline Total sperm length & $273.50 \pm 16.58$ \\
Tail length & $264.07 \pm 16.57$ \\
Head length & $9.43 \pm 0.38$ \\
Nucleus length & $4.78 \pm 0.25$ \\
Perforator length & Not assessed \\
\hline
\end{tabular}


$(\mathrm{SD} \pm 17,22)$. The reasons for this high degree of variability in sperm morphometry is not known, but has already been highlighted by previous studies and is probably linked to sperm competition [14-15].

Morphological analysis revealed visible morphological defects such as broken tails, double tails and double heads. It is known that some elements during the collection and handling of sperm, such as temperature, centrifugation or freezing, can influence sperm viability and induce morphological changes.

In our experiment, the sperm manipulation was minimal since the collection of spermatozoa was performed by washing and centrifugation of the testes and seminal vesicles, ensuring a high percentage of vital and morphologically normal spermatozoa. Moreover, centrifugation was performed at $250 \mathrm{~g} \times 10 \mathrm{~min}$, this combination falls within the range sug gested by Collins [16], so we can be sure that no damages and changes to sperm morphology have been caused by sperm manipulation.

It is more likely that the presence of morphologically altered spermatozoa could be determined by genetic and / or environmental factors, which could have modified the normal gametogenesis process. Conversely to mammals, drones emerge from their comb cells with the entire pool of sperm formed [17], so we suggest that if any alterations are found in the spermatozoa of mature drones they are likely to occur during larval stages, therefor morphology and morphometry should not be influenced by age. Furthermore, alterations were observed in the semen collected by drones of the same apiary, making it possible to hypothesize that there may be an external factor that strongly influenced the formation of morphologically altered sperm. Unfortunately, in this case, it was not possible to identify the actual cause of the alterations.

\section{Conclusion}

In conclusion, the results obtained, despite the low number of samples analysed, the limited area and time of sampling, allow a preliminary definition of the standard measures of the Italian honeybee spermatozoa. Further studies are necessary to collect more data in order to build a standard that could be used to outline any alterations.

\section{Competing interests}

The authors declare they have no competing interests.

\section{Authors' contributions}

\begin{tabular}{|l|c|c|c|c|c|c|c|}
\hline Authors' contributions & KP & ED & MM & SA & FC & VP & PM \\
\hline Research concept and design & $\checkmark$ & $\checkmark$ & -- & -- & -- & -- & -- \\
\hline Collection and/or assembly of data & $\checkmark$ & $\checkmark$ & -- & $\checkmark$ & -- & -- & -- \\
\hline Data analysis and interpretation & -- & -- & $\checkmark$ & $\checkmark$ & $\checkmark$ & -- & -- \\
\hline Writing the article & $\checkmark$ & -- & $\checkmark$ & -- & -- & -- & -- \\
\hline Critical revision of the article & -- & -- & -- & -- & -- & $\checkmark$ & $\checkmark$ \\
\hline Final approval of article & $\checkmark$ & $\checkmark$ & $\checkmark$ & $\checkmark$ & $\checkmark$ & $\checkmark$ & $\checkmark$ \\
\hline Statistical analysis & -- & -- & -- & -- & $\checkmark$ & -- & -- \\
\hline
\end{tabular}

\section{Publication history}

Editor: Franz-Josef Kaup, German Primate Center, Germany.

Received: 01-May-2019 Final Revised: 01-Jun-2019

Accepted: 04-Jun-2019 Published: 28-Jun-2019

\section{References}

1. Goulson D, Nicholls E, Botias C and Rotheray EL. Bee declines driven by combined stress from parasites, pesticides, and lack of flowers. Science. 2015; 347:1255957. | Article | PubMed

2. Straub L, Villamar-Bouza L, Bruckner S, Chantawannakul P, Gauthier L, Khongphinitbunjong K, Retschnig G, Troxler A, Vidondo B, Neumann P and Williams GR. Neonicotinoid insecticides can serve as inadvertent insect contraceptives. Proc Biol Sci. 2016; 283. I Article I PubMed Abstract | PubMed FullText

3. Kairo G, Provost B, Tchamitchian S, Ben Abdelkader F, Bonnet M, Cousin $M$, Senechal J, Benet P, Kretzschmar A, Belzunces LP and Brunet JL. Drone exposure to the systemic insecticide Fipronil indirectly impairs queen reproductive potential. Sci Rep. 2016; 6:31904. | Article | PubMed Abstract I PubMed FullText

4. Kumar $\mathrm{N}$ and Singh AK. Trends of male factor infertility, an important cause of infertility: A review of literature. J Hum Reprod Sci. 2015; 8:191-6. | Article | PubMed Abstract | PubMed FullText

5. Carreck NL, Andree M, Brent CS, Cox-Foster D, Dade HA, Ellis JD, Hatjina $F$ and van Englesdorp D. Standard methods for Apis mellifera anatomy and dissection. J Apicul Res. 2013; 52:1-40. | Article

6. Abu Hassan Abu D, Franken DR, Hoffman B and Henkel R. Accurate sperm morphology assessment predicts sperm function. Andrologia. 2012; 44 Suppl 1:571-7. | Article | PubMed

7. Gatimel N, Moreau J, Parinaud J and Leandri RD. Sperm morphology: assessment, pathophysiology, clinical relevance, and state of the art in 2017. Andrology. 2017; 5:845-862. | Article | PubMed

8. Jamieson BGM. The Ultrastructure and Phylogeny of Insect Spermatozoa. Cambridge. University Press Cambridge. 1987.

9. Peng CYS, Yin CM and Yin LRS. Ultrastructure of honey bee, Apis mellifera, sperm with special emphasis on the acrosomal complex following high-pressure freezing fixation. Physiol Entomol. 1993; 18:9310. $\mid$ Article

10. Gontarz A, Banaszewska D, Gryzinska M and Andraszek K. Differences in drone sperm morphometry and activity at the beginning and end of the season. Turk J Vet Anim Sci. 2016; 40:598-602. | Article

11. Pitnick S. Investment in testes and the cost of making long sperm in Drosophila. Am Nat. 1996; 148:57-80. | Article

12. Boomsma JJ, Baer B and Heinze J. The evolution of male traits in social insects. Annu Rev Entomol. 2005; 50:395-420. | Article | PubMed

13. Rhodes JW, Harden S, Spooner-Hart R, Anderson DL and Wheen G. Effect of age, season and genetics on semen and sperm production in Apis mellifera drones. Apidologie. 2011; 42:29-38. | Article

14. Blengini CS, Sergio N, Gabriela C, Giojalas LC and Margarita C. Variability in sperm form and function in the context of sperm competition risk in two Tupinambis lizards. Ecol Evol. 2014; 4:4080-92. | Article I PubMed Abstract | PubMed FullText

15. Ros-Santaella JL, Pintus E and Garde JJ. Intramale variation in sperm size: functional significance in a polygynous mammal. PeerJ. 2015; 3:e1478. | Article | PubMed Abstract | PubMed FullText 
Power et al. Veterinary Medicine and Animal Sciences 2019,

http://www.hoajonline.com/journals/pdf/2054-3425-6-2.pdf

16. Collins AM. A scientific note on the effect of centrifugation on pooled honeybee semen. Apidologie. 2003; 34:469-470. | Article

17. Baer B. Sexual selection in Apis bees. Apidologie. 2005; 36:187-200. | Article

\section{Citation:}

Power K, D’Anza E, Martano M, Albarella S, Ciotola F, Peretti V and Maiolino P. Morphological and morphometric analysis of the Italian honeybee (Apis mellifera ligustica) spermatozoa: a preliminary study in Campania region. Vet Med Anim Sci. 2018; 6:2. http:// dx.doi.org/10.7243/2054-3425-6-2 